\title{
THE SYNTHESIS AND CHARACTERIZATION OF POLYPEPTIDE-ADRIAMYCIN CONJUGATES AND ITS COMPLEXES WITH ADRIAMYCIN. PART I
}

\author{
W.A.R. van Heeswijk, C.J.T. Hoes, T. Stoffer, M.J.D. Eenink, W. Potman and J. Feijen \\ Department of Chemical Technology, Twente University of Technology, Enschede (The Netherlands)
}

(Received January 3, 1985; accepted in revised form March 12, 1985)

Poly( $\alpha$-L-glutamic acid) (PGA) was grafted with amino acid and oligopeptide spacers up to 5 amino acids with the use of $\mathrm{N}, \mathrm{N}^{\prime}$-carbonyldiimidazole and 2,3-dihydro-1,2-benzisothiazole-3-on-1,1-dioxide (saccharin) as an additive, and these polypeptides were characterized. The antitumor antibiotic adriamycin was covalently coupled via an amide bond onto PGA and onto the grafted polymers with the use of N-ethoxycarbonyl-2-ethoxy1,2-dihydroquinoline (EEDQ); these conjugates were characterized. The conjugates containing Gly-Gly-L-Leu spacer arms did yield free adriamycin upon digestion with papain. Adriamycin gave fairly stable complexes with PGA-adriamycin and branched polypeptideadriamycin conjugates; these complexes were characterized.

\section{INTRODUCTION}

Major problems in the administration of cytostatic agents are the lack of specificity of the drug for the tumor cell, the toxic side effects and the development of resistence of tumors for a particular drug. Extracellular polymeric release systems can be applied to maintain constant levels of the drug in a particular body compartment for extended periods of time. Examples of these systems are the well known DNA. anthracycline complexes developed by Trouet et al. [1]. The release of the drug from these systems is at least partially governed by the clearance of plasma from the free drug, which in turn leads to further dissociation of the DNA complexes. In principle, constant levels of the drug can also be obtained by bioerosion of degradable polymer matrices or by extracellular cleavage of covalently bound polymer-drug conjugates.
Although peak concentrations of the drug can be avoided using these systems and a decrease in systemic toxicity can be expected, a more selective administration of the drug would be advantageous. This could be achieved with the use of endocellular release systems, which release the drug after being incorporated by tumor cells. Only after uptake by tumor cells should the conjugates degrade and release the parent drug.

Tumor cells show a higher degree of uptake of macromolecules by endocytosis than their normal counterparts do. After internalization of the polymer-drug conjugate, a phagosome is formed which fuses with a lysosome, and subsequently the polymer-drug conjugate is exposed to a mixture of at least 40 digestive enzymes at an acidic $\mathrm{pH}(4 \sim 5)$.

Information on the presence and activity of specific enzymes in the lysosomal compartments can be used to design polymer- 
drug conjugates in which the drug is coupled to the macromolecular carrier through spacers which can be easily cleaved by the enzymes involved [2]. Macromolecular prodrugs can be designed which, by virtue of the presence of high levels of specific enzymes at the tumor cell membrane ( $\gamma$-glutamyl transferase) [3] or near the tumor (plasmin), rapidly release the drug at the membrane or in the immediate surroundings of the tumor [4].

Problems which still exist are the competitive uptake of macromolecular prodrugs by endocytosing cells, e.g. RES, which in principle can be avoided by the coupling of appropriate antibodies against the tumor cells onto the polymer-drug conjugate. In this paper we have concentrated on the development of high molecular weight prodrugs of adriamycin using poly( $\alpha$-L-glutamic acid) as a biodegradable carrier and different peptides as spacers. These systems were characterized with respect to composition and load of adriamycin by spectroscopic and chemical methods.

\section{RESULTS AND DISCUSSION}

\section{a. Prodrug design}

Polymeric systems of anthracyclines which have been investigated include: DNA (adriamycin [5] and daunomycin [1]); antibodies and fab dimers (daunomycin [6-8] and adriamycin [9]); bovine serum albumin (daunorubicin [10]) and various other proteins (daunorubicin [11]); poly(D-lysine) (daunomycin [9]); polyglutamic acid (adriamycin salt [12]); poly $\left(N^{5}\right.$-hydroxypropylL-glutamine) (adriamycin hydrazone [13]); polyaspartic acid (daunorubicin [14]); lectins (daunomycin [15]); dextran (daunorubicin $[13,16]$ ); polyglutaraldehyde (adriamycin [12]) and a copolymer of 2-(hydroxy)ethyl methacrylate and vinylpyrrolidone (daunorubicin [17]).

Polyglutamic acid (PGA) and derivatives have also been used as carriers for mustard compounds [18], cyclophosphamide [19], Ara-C [20] and steroid hormones [2125]. Poly ( $\alpha$-amino acids) were also used as biodegradable matrices for the release of bioactive compounds [26-28]. PGA possesses factor VIII-like coagulant activity [29] and PGA has been tested as a plasma expander [30]. Adriamycin yields a waterinsoluble salt with PGA which showed antitumor activity and greatly reduced toxicity in mouse mammary experiments [12].

We have concentrated on the use of PGA as a carrier, because this polymer can be readily degraded by lysosomal enzymes, is rather plasma stable and contains sufficient reactive groups for derivatization. After partial derivatization the conjugate will still be water-soluble owing to residual carboxylate groups. PGA is not expected to be toxic in the quantities required for the use as a carrier and can be readily obtained with different molecular weight distributions.

The interpolation of appropriate spacers between carrier and the bioactive compound to meet optimal requirements for lysosomal attack and release of the drug has been applied by several investigators $[2,10,31]$. Thus, Trouet et al. [10] have shown that optimal spacers consisted of tri- and tetra-LLeu-terminal peptides attached to succinylated $\epsilon$-lysine groups of albumin. Kopecek [2] described the peptide-spacer dependent release of $p$-nitroaniline from $N$-(2-hydroxypropyl)methacrylamide using thiolproteinases (Cathepsin B, L and $\mathrm{H}$ ) as important representatives of the lysosomal enzyme population. Because both the length and the composition of the spacer are of great importance we have synthesized and characterized a number of conjugates with various spacer arms (1-5 amino acid residues). Tyrosine was incorporated in two of the systems to enable labeling with radioactive tracers which should aid in the study of biodegradation of the conjugate (Table 2).

Adriamycin displays a tendency to selfassociation in aqueous solution, resulting 
in dimers, and even higher oligomers [32, 33] due to the hydroquinone-quinone like structure in the aglycon. It can be expected that free adriamycin might yield relatively strong charge transfer complexes with the covalently bound drug in the conjugates. The application of a negatively charged carrier such as PGA might greatly add to the stability of these complexes.

\section{b. Synthesis and characterization}

Polyglutamic acid (PGA) was prepared according to Blout et al. [34-36] (Scheme 1) by triethylamine-initiated polymerization of L-glutamic acid 4-benzyl ester [37] $\mathrm{N}$ carboxyanhydride [38] in toluene and subsequent debenzylation of the polymers obtained with the use of hydrogen bromide (Scheme 1). Molecular weights $\left(\bar{M}_{\mathrm{v}}\right)$ of the polymers typically ranged from 50,000

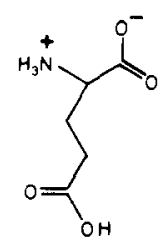

Glutamic acid

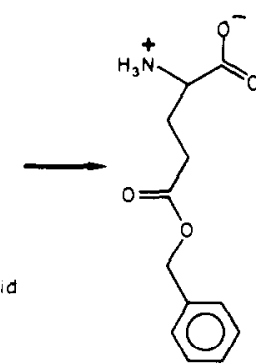

$y$-Benzyl glutamate

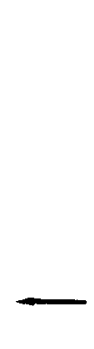

Poly glutamic acid

Scheme 1. Synthesis of poly( $\alpha$-L-glutamic) acid up to 350,000 daltons. Residual benzyl groups mounted up to 5\% (UV spectrometry) (Table 1). Both variables $\left(\bar{M}_{\mathrm{v}}\right.$ and residual groups) largely depend on the conditions employed during the debenzylation procedure. The material obtained as described (experimental, Table 1) was free of microgel particles and readily dissolved in dimethylformamide.

In our efforts to attach adriamycin directly onto PGA we found that the majority of the well established techniques used in peptide synthesis were not suitable or gave erratic results due to the nature of both the carboxylic component (PGA) and the amine (adriamycin). First, activation of PGA with carbodiimides $[39,40]$ or Woodward reagent $\mathrm{K}$ [41] also gave rise to the incorporation of $\mathrm{N}$-acylisourea derivatives, which do not further react with nucleophiles. Secondly, it has been shown $[42,43]$ that overactivation of lateral carboxylic groups in glutamic and aspartic acid containing peptides may result in the formation of cyclic imides, which, in turn, are likely to isomerise into the corresponding $\omega$-peptides or even may result in chain scission. The latter fragmentation became a serious side reaction with the use of $N, N^{\prime}$-carbonyl diimidazole (CDI) [44]. Thus, addition of CDI to a stirred

\section{TABLE 1}

Molecular weight, $\bar{M}_{\mathrm{v}}$, and residual benzyl groups of poly $(\alpha-\mathrm{L}$-glutamic acid) (PGA)

\begin{tabular}{lll}
\hline Batch & $\bar{M}_{\mathrm{v}}{ }^{\mathrm{a}}$ & $\begin{array}{l}\text { Residual benzyl groups } \\
(\mathrm{mol} \%)\end{array}$ \\
\hline $\mathrm{PGA}_{2}$ & $1.3 \times 10^{5}$ & 5 \\
$\mathrm{PGA}_{3}$ & $3.0 \times 10^{4}$ & $<0.5$ \\
$\mathrm{PGA}_{4}$ & $2.5 \times 10^{5}$ & $<0.5$ \\
$\mathrm{PGA}_{7}{ }^{\mathrm{a}}$ & $3.5 \times 10^{5}$ & 2.5
\end{tabular}

${ }^{\text {a }}$ Determined by viscometry using the relation $[\eta]=$ $3.13 \times 10^{3}\left(\bar{M}_{\mathrm{v}}\right)^{0.965}[50-52]$.

${ }^{b}$ Determined by UV spectrometry using $\gamma$-benzylL-glutamate as a reference compound.

${ }^{c}$ Deprotection was accomplished by transfer hydrogenation of poly- $\gamma$-L-benzylglutamate [53]. 
solution of PGA in dimethylformamide resulted in a rapid decrease in viscosity and poor recoveries of PGA after dialysis. Moreover, in view of the polyfunctionality of adriamycin (amine, ketone, quinone, hydroquinone, phenolic $\mathrm{OH}$, primary, secondary and tertiary $\mathrm{OH}$ and the sensitive 2-deoxyglycoside acetal) the conditions of coupling of the drug onto the polymer must be compatible with the structure elements present. This implies that the great majority of methods for the establishment of covalent bonds, including those based on oxidation-reduction reactions [45], is not suitable and lays a number of restrictions during coupling and work-up of products. Selective coupling of the amino group in the daunosamine moiety without concomitant formation of esters also greatly
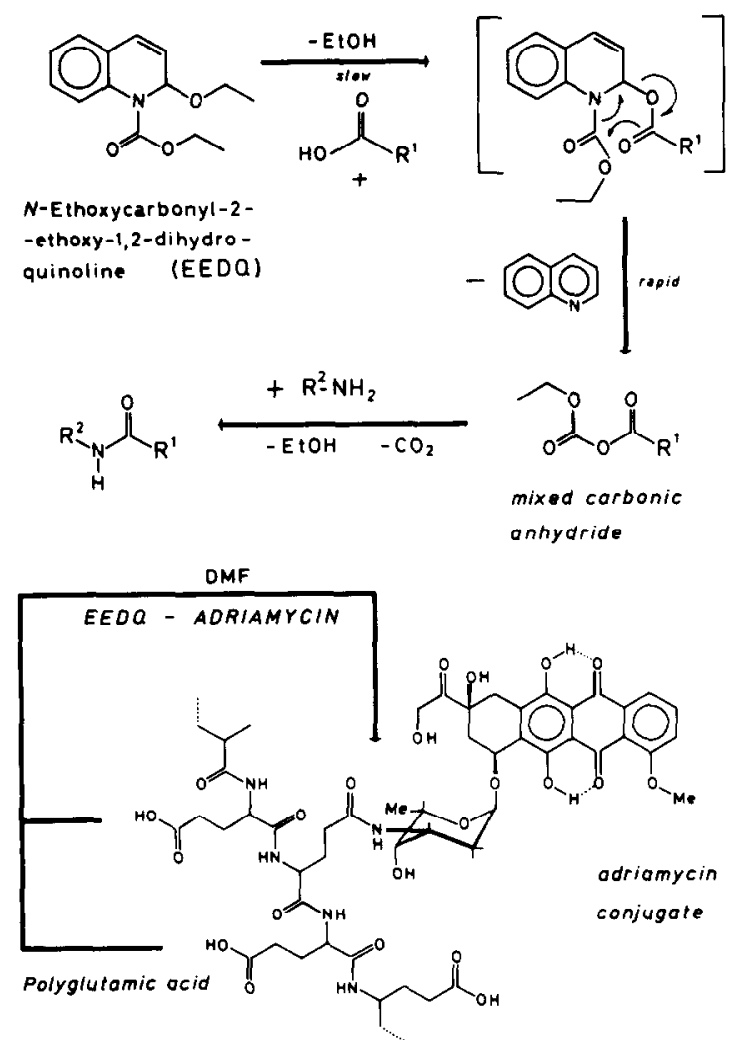

Scheme 2. Direct conjugation of adriamycin onto PGA via an amide bond using EEDQ. reduces the number of methods available. We have found that the use of $N$-ethoxycarbonyl-2-ethoxy-1,2-dihydroquinoline

(EEDQ) [46, 47] did meet our requirements. This compound is known to react with carboxylic acid groups with the formation of mixed carbonic anhydrides (Scheme 2). However, we observed that these mixed anhydrides disproportionate into symmetrical acid anhydrides. Thus, addition of EEDQ to a solution of PGA in dimethylformamide gave rise to a solid transparent gel within $30 \mathrm{~min}$ due to the formation of acid anhydride crosslinks. These crosslinks are hydrolysed by water, which ultimately results in redissolution of the gels. In the presence of equimolar amounts of adriamycin, these gels are not formed. This observation provides additional chemical evidence for the formation of both symmetrical acid anhydrides and the amides anticipated. A slight excess of EEDQ in the reaction mixture also gave rise to the formation of transparent gels after $24 \mathrm{~h}$ at which time virtually all of the drug has been incorporated into the polymer. However, the crosslinks present in these gels are much more resistant towards hydrolysis than those of the acid anhydride type. It was concluded, that these crosslinks were, at least partly, of an estertype nature. It was found that these ester bonds are selectively hydrolysed in the course of $2-3$ days in the presence of imidazole. The hydrolysed material readily passed a $0.45 \mu \mathrm{m}$ Millipore filter and the conjugate was purified and isolated by dialysis, ultrafiltration, chromatography and lyophylization. The UV spectrum and the molar extinction were essentially the same as those of the free drug. Both the pure conjugates and mixtures with the free drug did follow Lambert Beer's law. These findings enabled accurate measurements of the bound drug in the conjugate. In a high frequency NMR spectrum (500 $\mathrm{MHz})$ both the $C^{\prime}$ 6-methyl doublet of the daunosamine moiety and the $\mathrm{MeO}$ singlet (aglyconic portion) were discernible. 


\section{TABLE 2}

Covalently bound prodrugs ${ }^{2}$ of adriamycin (ADR) derived from poly( $\alpha$-glutamic acid) (PGA)/oligopeptide grafts

\begin{tabular}{|c|c|c|c|c|c|c|}
\hline $\begin{array}{l}\text { Batch of PGA } \\
\text { (Table 1) }\end{array}$ & Spacer & $\begin{array}{l}\text { Spacer load } \\
(\text { mol\%) }\end{array}$ & $\begin{array}{l}\text { ADR loa } \\
\text { (mol\%) }\end{array}$ & (wt\%) & $\begin{array}{l}\text { Yield of oligo- } \\
\text { peptide graft } \\
\text { (by wt\%) }\end{array}$ & $\begin{array}{l}\text { Yield of ADR- } \\
\text { prodrug } \\
\text { (by wt\%) }\end{array}$ \\
\hline $\mathbf{P G A}_{4}$ & none & - & 6 & 16 & - & 96 \\
\hline $\mathrm{PGA}_{3}$ & none & - & 5 & 15 & - & 84 \\
\hline $\mathrm{PGA}_{4}$ & Gly-Leu & 100 & 4.2 & 6.6 & 85 & 58 \\
\hline $\mathrm{PGA}_{3}$ & $\mathrm{Gly}-\mathrm{Gly}-\mathrm{Leu}$ & 76 & 4 & 7 & N.D. ${ }^{b}$ & N.D. ${ }^{b}$ \\
\hline $\mathrm{PGA}_{3}$ & Gly-Gly-Leu & 91 & 10 & 12 & 91 & 77 \\
\hline $\mathrm{PGA}_{4}$ & Gly-Gly-Leu & 91 & 8.3 & 11 & 92 & 83 \\
\hline $\mathrm{PGA}_{4}$ & Gly-Gly-Leu & 95 & - & - & 77 & - \\
\hline $\mathrm{PGA}_{2}$ & (Gly)-(Gly-Gly-Leu) & $95^{c} / 67^{d}$ & 10 & 13 & $60^{c} / 93^{d}$ & 89 \\
\hline $\mathrm{PGA}_{3}$ & $($ Gly-Tyr $)-(\text { Gly-Leu })^{e}$ & $77^{\mathrm{c}} / 34^{\mathrm{d}}$ & 3.6 & 5.0 & 90 & 82 \\
\hline $\mathrm{PGA}_{3}$ & $($ Gly-Tyr $)(\text { Gly }- \text { Gly-Leu })^{e}$ & $100^{c} / 53^{d}$ & 9.1 & 9.1 & 73 & 92 \\
\hline $\mathrm{PGA}_{7}$ & $($ Gly - Tyr $)-(\text { Gly }- \text { Gly -Leu })^{e}$ & $100^{c} / 67^{d}$ & 3.3 & 3.3 & 40 & 56 \\
\hline
\end{tabular}

${ }^{a}$ Sodium salt.

${ }^{b}$ Not determined.

c First spacer fragment.

'Second spacer fragment.

eascade coupling of respective spacers (see Experimental).

Results are given in Table 2. In early preparations we were faced with difficulties in removing small amounts of free (extractable) drug from the conjugates. These amounts seemed to be bound to the conjugate by relatively stable charge transfer complexes (adriamycin itself exists as dimers in solution $[32,33])$. By analogy with relatively stable anthracycline-DNA complexes [1, 5], the surprising stability of the present conjugate-free drug complexes can be ex- plained by the additional formation of ion pairs $\left(\mathrm{COO}^{-}, \mathrm{NH}_{3}^{+}\right)$. Both the presence of covalently bound drug and free carboxylic acid groups are required for the formation of these complexes. Addition of the free drug to PGA led to the formation of a voluminous precipitate. Thus, apart from being a prodrug, the conjugate itself may also serve as a carrier for the free drug. These conjugate complexes are readily prepared either by (a) the mere addition of

\section{TABLE 3}

Complexes of adriamycin (ADR) and conjugates of adriamycin derived from PGA and PGA graft (Table 2)

\begin{tabular}{|c|c|c|c|c|c|}
\hline \multirow[t]{2}{*}{ Conjugate } & \multicolumn{2}{|c|}{ Covalently bound ADR } & \multicolumn{2}{|c|}{ Complex bound ADR } & \multirow{2}{*}{$\begin{array}{l}\text { Yield of complex } \\
\text { (by wt\%) }\end{array}$} \\
\hline & $(\mathrm{mol} \%)$ & $(w t \%)$ & $(\mathrm{mol} \%)$ & $(w t \%)$ & \\
\hline $\mathrm{PGA}_{4}-\mathrm{ADR}$ & 6 & 16 & 3.3 & 8.8 & $51^{a}$ \\
\hline $\mathbf{P G A}_{3}$ ADR & 5 & 15 & 3.3 & 9.3 & 93 \\
\hline $\mathrm{PGA}_{3}$-Gly-Gly-Leu-ADR & 4 & 7 & 2.9 & 4.4 & 89 \\
\hline
\end{tabular}

${ }^{a}$ Low yield due to gel formation of conjugate. 
the free drug to the conjugate or (b) by directly coupling adriamycin to PGA using 0.5-0.6 equimolar amounts of EEDQ with respect to the free drug. In contrast to aqueous solutions of adriamycin hydrochloride, these conjugate complexes were stable at physiological $\mathrm{pH}$ for long periods of time. Results are given in Table 3.

In our approach to interpolate oligopeptide spacers between the carrier and the drug, we preferred a different synthetic strategy than Trouet et al. [10] on the following considerations: Firstly, in view of the expense of the drug, a route which allows coupling of adriamycin in the very last step of the synthesis is more attractive than being engaged in a tedious multistep synthesis in which considerable amounts of the anthracycline are lost. Secondly, the preparation of carriers, which already contain the spacer arms desired will, eventually, be attractive for use in applications with other drugs. In the present approach, we preferred the use of commercially available $C$-unprotected oligopeptides. To discriminate between the carboxylic groups of PGA and those of the oligopeptides introduced, preactivation of PGA prior to addition of the oligopeptide is essential.

As mentioned above, the preactivation of lateral carboxylic acid groups in PGA by CDI proved to be successful, but gave rise to extensive fragmentation of the peptide chain. By analogy with other methods of preactivation, a number of additives were tried. Saccharin (2,3-dihydro-1,2-benzisothiazole-3-on-1,1-dioxide) proved to be very successful. Saccharin imides [48] have been advocated for use in peptide synthesis but the method has gained little interest, probably due to difficulties in their preparation (i.e. formation of $\mathrm{DCC}$-saccharin adducts or the use of highly reactive chemicals such as thionyl chloride) [48]. We have found that the addition of CDI to a solution containing both the carboxylic component and a slight excess of saccharin resulted in the smooth generation of these imides in essentially quantitative yield and with only slight concomitant fragmentation of the polypeptide chain. Moreover, these polymeric imides proved to be sufficiently reactive to condense in high yields with the tetramethylguanidinium salts of the oligopeptides of choice in DMF. The chemistry of the method is depicted in Scheme 3, and results are given in Table 2 . Both saccharin and imidazole, being the sole nontoxic and water-soluble byproducts of the reaction, were readily removed by dialysis and molecular filtration, whereas the tetramethyl guanidinium ions $\left({ }^{1} \mathrm{H}-\mathrm{NMR}\left(\mathrm{D}_{2} \mathrm{O}\right)\right.$ $\delta \quad 3.0 \mathrm{ppm}$ ) were exchanged quantitatively by sodium ions using ion-exchange chromatography. Theoretically, a partial transfer of the saccharinic imides from PGA to the carboxyl groups of the spacer may result in products in which some of these spacers are dimeric on the PGA-backbone and some of the PGA carboxyl groups are unreacted.

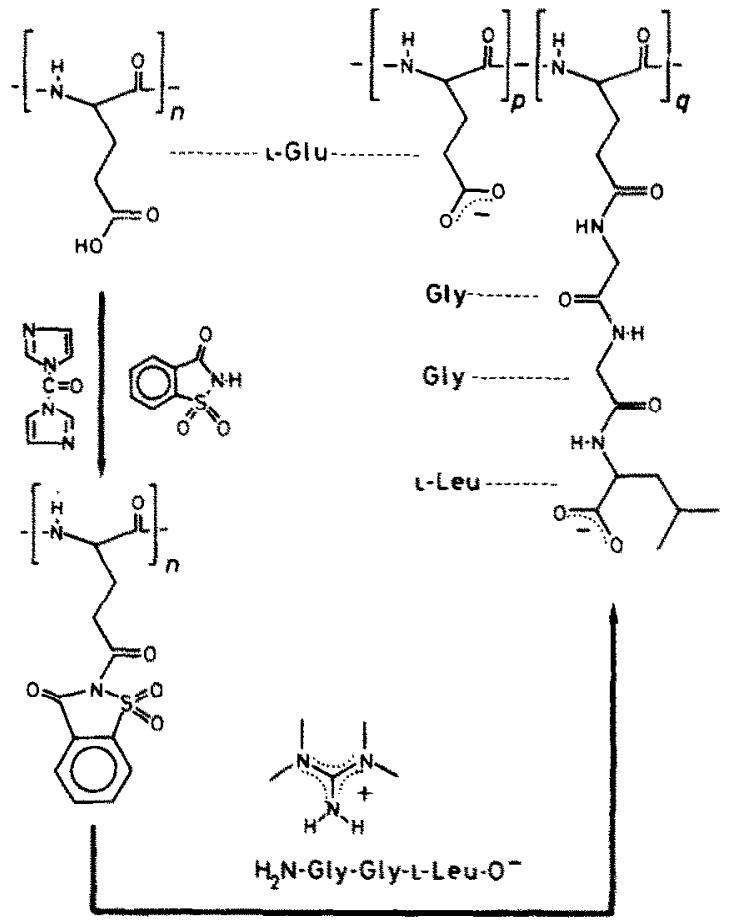

Scheme 3. Grafting of PGA with Gly-Gly-Leu tripeptide using the CDI-saccharin method. 


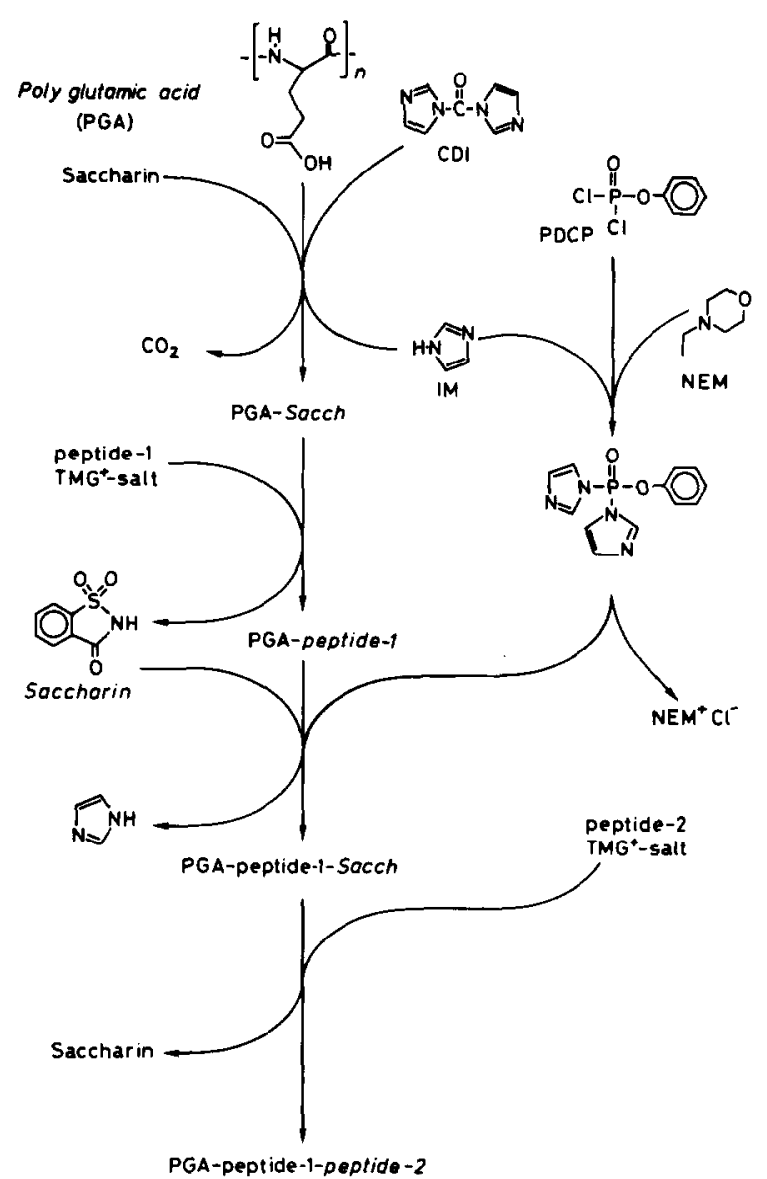

Scheme 4. Stepwise elongation (cascade technique) of oligopeptide spacers with the use of phenyl dichlorophosphate (PDCP).

However, such an imide transfer has not been observed in fragment condensations in which $C$-unprotected substrates were used [48]. The simplicity of the present method also prompted us to investigate the possibility of stepwise elongation of the peptide spacer arms without the isolation of intermediate products. This was accomplished readily with the use of phenyl dichlorophosphate [49] (PDCP) in DMF. The latter compound smoothly reacts with imidazole already present in the reaction mixture, thereby generating the corresponding phosphoryl diimidazolides, which in turn reactivate the $C$-terminal of the spacer arms giving the saccharin imides anticipated.
The chemistry of the cascade coupling method is depicted in Schemes 3 and 4. Oligopeptide spacer arms containing up to 5 amino acid residues (Gly-Tyr-Gly-GlyLeu) were readily prepared by this method (Table 2) using Gly-Tyr and Gly-GlyLeu in the CDI-saccharin and PDCP cascade methods, respectively. Degrees of incorporation of both oligopeptide fragments were obtained from the proton integrals attributable to appropriate isolated signals in the ${ }^{1} \mathrm{H}$ NMR spectra (e.g. Tyr-Ar-H and Leu- $\mathrm{CH}_{3}$ vs. Gly- $\mathrm{\beta}-\mathrm{CH}_{2}$ and total of all integrals, Fig. 1). However, in one experiment (Table 2) in which the first spacer fragment (GlyTyr) was coupled in 77 mole percent, a part of the second spacer fragment (GlyLeu) may be coupled directly to the carboxylic groups which are left unreacted in the first coupling step. A slight modification of the method was necessary using glycine. The latter amino acid was applied using the corresponding t-butyl ester, rather than its TMG salt. The protecting group was removed quantitatively with the use of trifluoroacetic acid. The grafted polymers were isolated either as the sodium or as the pyridinium salts. In contrast to PGA, the free acids of these polymers were sticky gums which were difficult to handle.

Finally, adriamycin was coupled to the grafted polymers (pyridinium salts) with the use of EEDQ, and isolated, purified and analysed for the drug as described for PGA with slight modifications. Results are given in Table 2 .

In contrast to the conjugates in which the drug was attached directly onto the carrier, the prodrugs in which peptide spacers were interpolated between the PGA backbone and the drug (Fig. 2) readily yielded free adriamycin upon digestion with a relatively aspecific protease like papain.

The voluminous coloured conjugates were stable at $-20^{\circ} \mathrm{C}$ over prolonged periods of time. However, the batches derived from high molecular weight PGA ( $\bar{M}_{\mathrm{v}}$ 200,000) had a tendency to age, resulting in slow or 


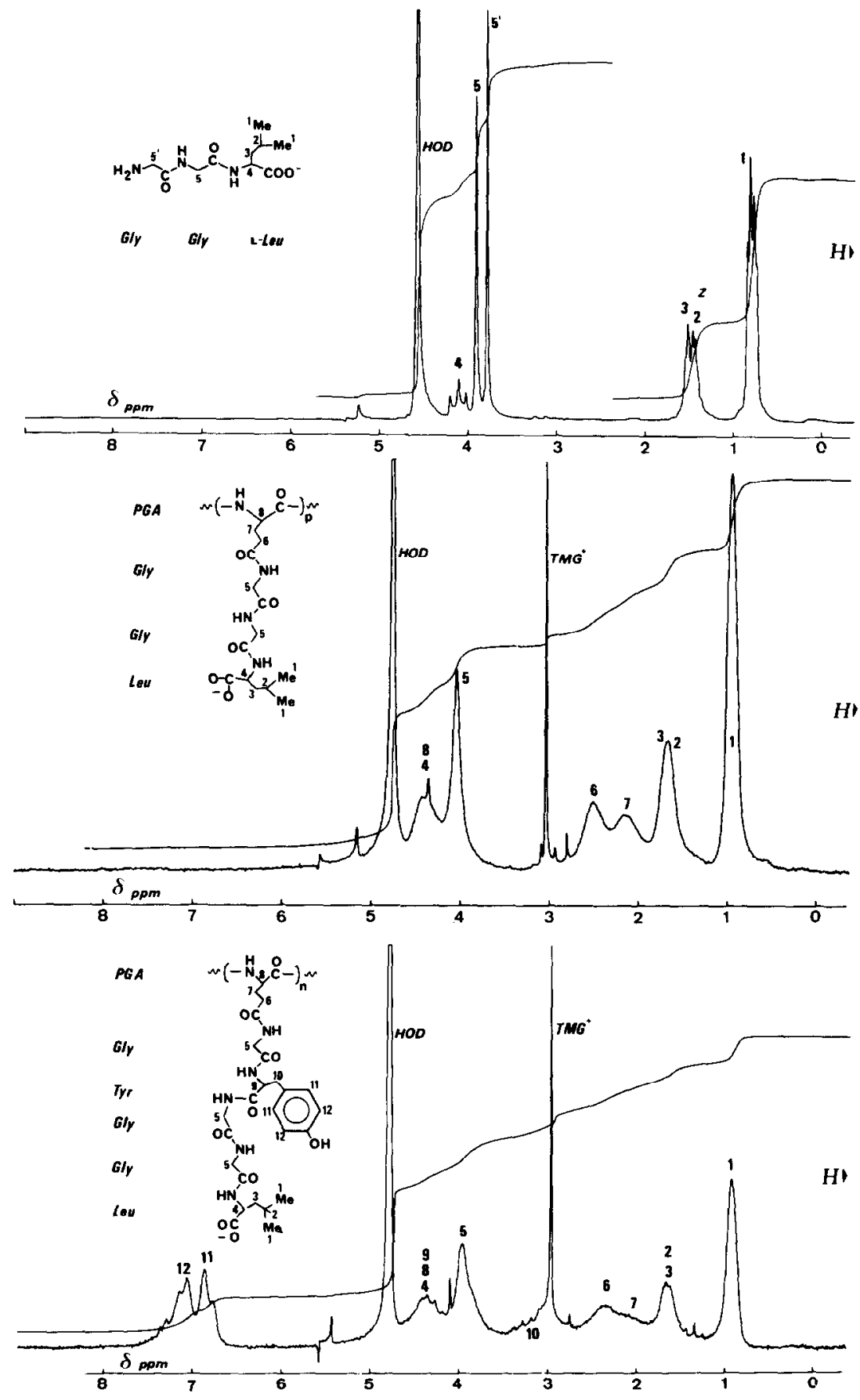

Fig. 1. Interrelated ${ }^{1} \mathrm{H}-\mathrm{NMR}\left(80 \mathrm{MHz}, \mathrm{D}_{2} \mathrm{O}\right)$ spectra and assignments of $\mathrm{Gly}-\mathrm{Gly}-\mathrm{Leu}$, and the polypeptide grafts PGA-Gly-Gly - Leu and PGA-Gly-Tyr-Gly-Gly-Leu, respectively. 


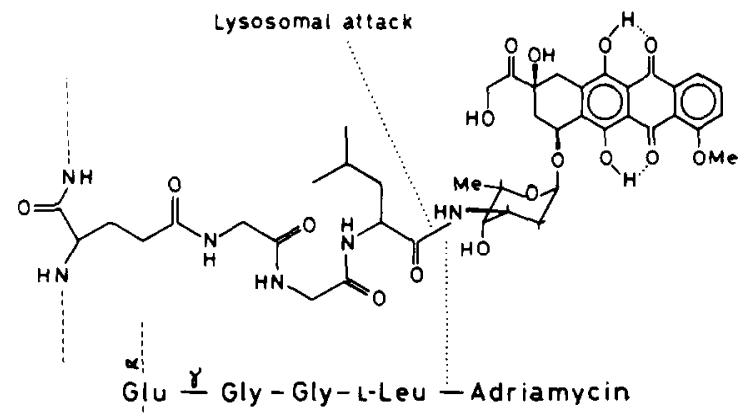

Fig. 2. Monomeric unit in protease-activated macromolecular prodrug of adriamycin.

even poor solubility in water and the reformation of microgel particles. The branched conjugates also had a tendency to give charge transfer complexes with free adriamycin (Table 3), albeit not with the extreme stability as was found for the conjugates not containing the spacer arms. Surprisingly, these complexes were more stable upon storage and did redissolve more readily than the conjugates from which they were prepared. Thus, apart from being interesting devices both in terms of controlled extracellular release of the (complexed) drug and endocellular release of the (covalently bound) drug, the present complexes are stable formulations at physiological $\mathrm{pH}$ for both the prodrug and free adriamycin.

\section{MATERIALS AND METHODS}

Tetrahydrofuran (NCA preparation) was stirred with finely powdered potassium hydroxide $(10 \mathrm{~g} / \mathrm{l})$, filtered and distilled from calcium hydride under a nitrogen atmosphere. Toluene used for the polymerization of NCA was dried azeotropically. Pyridine (1 l) was distilled from chlorosulphonic acid $(10 \mathrm{ml})$ and distilled. Dimethylformamide (spectrograde) was purchased from Janssen (Belgium). All chemicals used, including oligopeptides (Pierce Chem. Comp.) are commercially available. Smallscale reactions were conducted in Reacti vials (Pierce Chem. Comp.). ${ }^{1} \mathrm{H}-\mathrm{NMR}$ spectra (internal $\mathrm{Me}_{4} \mathrm{Si}\left(\mathrm{CDCl}_{3}\right.$, DMSO $\left.d_{6}\right)$ or sodium 2,2-dimethyl-2-silapentane-5-sulfonate in $\mathrm{D}_{2} \mathrm{O}$ ) were recorded with Bruker WP 80 (80 MHz) and Bruker WM 500 (500 MHz) spectrometers. TLC was performed on silica gel (Merck Kieselgel 60 F254) using n-butanol-acetic acid-water $(4: 1: 1)$ as the eluent. Spots were visualised with ninhydrin spray and/or UV light (245 $\mathrm{nm}$ ). Immersible molecular filters (CX-10), filters (HA $0.45 \mu \mathrm{m}$ ) and a stirred pressured cell (XX42.04710) were purchased from Millipore Benelux, Belgium.

\section{Poly $(\alpha$-glutamic acid)}

Glutamic acid 5-benzylester [37] $N$ carboxyanhydride [38] (10 g, $38 \mathrm{mmol}$, m.p. $92-93.5^{\circ} \mathrm{C}$ ) was polymerized in toluene (1 l) under a blanketing atmosphere $\left(\mathrm{N}_{2}\right.$, room temperature, 5 days) using triethylamine (200 $\mu 1,1.44 \mathrm{mmol})$ as the initiator. Then, a brisk stream of hydrogen bromide was passed through the reaction mixture under vigorous stirring $(20 \mathrm{~min})$ and the mixture was allowed to stand overnight. The toluene was decanted and the polyacid was washed with portions $(100 \mathrm{ml})$ of fresh toluene $(2 x)$ and acetone $(5 x)$ until the washings were colorless.

The crude polyacid was stirred in sodium phosphate buffer (100 $\mathrm{mM}, 100 \mathrm{ml}$, pH 7) and aqueous sodium bicarbonate solution was added dropwise with stirring until a clear neutral solution resulted, which was dialyzed exhaustively against deionized water (Visking dialysis tubes 9-36/32 in, internal stirring with a slow stream of nitrogen), and filtered (Millipore $0.45 \mu \mathrm{m}$ ) with the aid of a stirred pressure cell (Millipore $\mathrm{XX} 42.04710)$. The filtered solution was acidificd $(\mathrm{HCl}, \mathrm{pH} 2)$, stirred $\left(40^{\circ} \mathrm{C}, 20\right.$ $\mathrm{min})$, and the precipitate was collected and washed with water. The fibrous wet mass was freeze dried (the air-dried compound dissolves less readily in dimethylformamide); yield was $3-4 \mathrm{~g}$. ${ }^{1} \mathrm{H}-\mathrm{NMR}$ 
and UV (sodium salt) spectra were indistinguishable from those reported [39]. Residual benzyl groups varied up to $5 \%$ (molar) as shown by UV measurements (250 nm, using L-glutamic acid 5-benzyl ester as the reference compound). Molecular weights of these polymers were determined by their intrinsic viscosity at $25^{\circ} \mathrm{C}$ in $0.2 \mathrm{M} \mathrm{NaCl}$ solution [50-52] by [ $\eta]$ $(\mathrm{dl} / \mathrm{g})=3.13 \times 10^{3}\left(\bar{M}_{\mathrm{v}}\right)^{0.965} ;$ Table 1 .

Poly $\alpha$-L-glutamic acid anhydride cross-linked gel

Polyglutamic acid (50 $\mathrm{mg}, 0.39 \mathrm{mmol}$ ) was dissolved in dimethylformamide (1.34 $\mathrm{ml}$ ). Then, EEDQ (8.7 mg, $0.0352 \mathrm{mmol}$; $0.09 \mathrm{eq})$ was added with stirring. Viscosity drops rapidly in the course of 2-3 min, and then gradually increases. Stirring is virtually impossible after $20 \mathrm{~min}$, whereas after $45 \mathrm{~min}$ a solid rubbery gel results, indicating the formation of interchain symmetrical acid anhydrides. The fragmentated gel dissolves completely in the course of a few hours in an aqueous solution of sodium bicarbonate, and even more rapidly in the presence of imidazole $(1 M)$. The formation of a gel, however, does not occur in the presence of a relatively strong amine such as adriamycin $(>0.04 \mathrm{mmol})$, which provides additional chemical evidence for the generation of corresponding amides. The presence of a relatively weak amine, such as prazozine, does not hamper the formation of rubbery cross-linked gels.

Copolymer of L-glutamic acid and $3^{\prime}-N-$ - (5-L-glutaminyl) adriamycin

Polyglutamic acid (200 mg, $1.55 \mathrm{meq}$ ) was dissolved in dimethylformamide $(2-5$ $\mathrm{ml}$, depending on the molecular weight of the polymer). The viscosity must be such that mechanical manipulation and stirring in a small reaction vial is possible. Free adriamycin was generated in a separate reaction vial from its hydrochloric acid salt (54 mg, $0.093 \mathrm{mmol}$ ) in dimethylformamide ( $2 \mathrm{ml})$ containing $N$-ethyl morpholine $(20 \mu \mathrm{l}$,
$0.16 \mathrm{mmol}$ ), and subsequently transferred to the polymer solution. Additional dimethylformamide $(200 \mu \mathrm{l})$ may be necessary to transfer virtually all of the adriamycin. The resultant solution was stirred for $3 \mathrm{~h}$, EEDQ (26 mg, $0.11 \mathrm{mmol}$ ) was added, and the solution was stirred overnight. In preparations when using high molecular weight polyacid or larger excesses of EEDQ a translucent solid red gel containing cross-links of both the acid anhydride and 14-ester types may result. The solution or the gel, which was fragmentated mechanically, was stirred into a phosphate buffer $(80 \mathrm{ml}$, $100 \mathrm{mM}, \mathrm{pH} \mathrm{7)} \mathrm{solution} \mathrm{containing} \mathrm{imidazole}$ (1 $\mathrm{g})$ and the mixture was kept in the dark at $6^{\circ} \mathrm{C}$ for $3-5$ days with occasional shaking. A diluted sample from the bulk gave the same UV spectrum and molar extinction coefficient for bound adriamycin $\left(E_{490}=\right.$ $84900 \mathrm{l} \mathrm{mol}^{-1} \mathrm{~cm}^{-1}$ ) as found for the free drug. The clear red solution was dialyzed against deionized water, freed from minute amounts of microgel particles (Millipore HA filter $0.45 \mu \mathrm{m}$ ), concentrated and washed by molecular filtration (Millipore immersible filters CX-10). TLC analysis may reveal small amounts of free adriamycin bound to the polymer by $\Pi$-complexes. The conjugate can be purified by passing slowly the solution through an ion exchange column $(100 \times 4$ $\mathrm{cm}$, Dowex HCRW-2, sodium form). Finally, the pure conjugate is isolated by concentration (molecular filtration) to a small volume and lyophilization giving a brickred voluminous mass; yield: $80-90 \%$ (recovery, by weight), 90-100\% (conversion to bound adriamycin; UV).

Attempt to digest the copolymer $(5 \mathrm{mg})$ with papain $(5 \mathrm{mg})$ in phosphate buffer (pH 5.4) did not yield free adriamycin (TLC).

In a $500 \mathrm{MHz}\left(\mathrm{D}_{2} \mathrm{O}\right){ }^{1} \mathrm{H}-\mathrm{NMR}$ spectrum a small sharp singlet on the positive slope of the HOD resonance attributable to $\mathrm{MeO}$ $\mathrm{CH}_{3}$ (aglycone; $\delta 3.99 \mathrm{ppm}$ ) and a doublet (daunosamine; $\mathrm{C}^{\prime} 6-\mathrm{CH}_{3}, \delta \mathrm{1.164}, \mathrm{d}_{5}{ }^{\prime}{ }^{6}, 6.35$ $\mathrm{Hz}$ ) were discernable). Other resonances were obscured by the resonances of polyglutamic acid, Table 2. 
Complex of adriamycin and the copolymer of Lglutamic acid and $3^{\prime}-N-(5-L-g l u t a m i n y l)$ adriamycin

\section{Method a}

The copolymer above $(210 \mathrm{mg})$ was dissolved in water $(10 \mathrm{ml})$ and the solution was transferred to a small flask fitted with a screw cap holding a molecular filter (Millipore immersible filter $\mathrm{CX}-10$ ) attached to a vacuum line, a magnetic stirring bar and a septum outlet. Solutions were then introduced into the stirred cell with the aid of a syringe at a very slow rate which was controlled by the efflux from the stirred cell. In this manner a solution of adriamycin hydrochloride $(40 \mathrm{mg}, 0.069 \mathrm{mmol}$ ), water (5 $\mathrm{ml})$, phosphate buffer $(2 \mathrm{ml}, 100 \mathrm{mM}$, $\mathrm{pH} 7)$ and water $(250 \mathrm{ml})$, respectively, were introduced. No adriamycin was present in the filtrate of the cell, indicating that all of the drug added is accomodated by the polymer in the form of $\Pi$-complexes. The solution of the macromolecular complex was filtered (Millipore HA $0.45 \mu \mathrm{m}$ ) with the aid of a stirred pressure cell to remove any microgel particles, and the filtrate and washings were again concentrated to a small volume with the aid of an immersible molecular filter as described above. The polymeric drug was finally isolated by lyophylization (240 $\mathrm{mg}, 95 \%)$. The material behaved as one entity in dialysis, molecular filtration and gel chromatography (Sephadex G10), but was readily decomposed into the conjugate and free adriamycin by ionexchange chromatography (polystyrene, sulphonate type, sodium form) and TLC. The UV spectrum of the polymeric complex was virtually the same as that of adriamycin or its conjugate, Table 3 .

Method $b$ (incomplete covalent linkage of the drug onto polyglutamic acid)

Polyglutamic acid (200 $\mathrm{mg}, 1.55 \mathrm{mmol})$ was dissolved in dimethylformamide $(1 \mathrm{ml})$ and a suspension of adriamycin, generated from its hydrochloric acid salt (108 $\mathrm{mg}$, $0.186 \mathrm{mmol}), N$-ethyl morpholine $(25 \mu \mathrm{l})$ in dimethylformamide $(4 \mathrm{ml})$ was added. The solution was stirred for an hour, EEDQ (25 $\mathrm{mg}, 0.093 \mathrm{mmol}$ ) was added, and stirring was continued overnight. The contents of the vial were dissolved in phosphate buffer (100 ml, $100 \mathrm{mM}, \mathrm{pH} \mathrm{7.0)}$ and the solution was dialysed exhaustively with internal stirring by a slow stream of nitrogen. The solution was passed through a Millipore filter (HA $0.45 \mu \mathrm{m}$ ) and prior to lyophylization the filtrate was concentrated by molecular filtration as described in Method a. The material prepared was indistinguishable from that prepared according to Method a.

Polyglutamic acid glycylglycyl-L-leucine graft (PGAGly-Gly-L-Leu), using $N, N^{\prime}$-carbonyl diimidazole (CDI) [44] as the sole condensing agent

Polyglutamic acid (33 $\mathrm{mg}, 0.25 \mathrm{mmol}$ ) was dissolved in dimethylformamide $(1 \mathrm{ml})$; CDI (60 mg, $0.35 \mathrm{mmol}$ ) was added and the solution was stirred under rigid exclusion from moisture. The reaction between the two components was accompanied with the evolution of carbon dioxide and with a dramatic decrease in the viscosity of the solution. Then, a solution of Gly-Gly-LLeu $N, N, N^{\prime}, N^{\prime}$-tetramethyl guanidinium salt (TMG ${ }^{+}$, prepared by the slow addition of $N, N, N^{\prime}, N^{\prime}$-tetramethyl guanidine (TMG; 30 $\mu \mathrm{l}, 0.25 \mathrm{mmol}$ ) to a stirred suspension of finely powdered Gly-Gly-L-Leu in dimethylformamide $(4 \mathrm{ml})$ ) was added. Stirring was continued for three days. The solution was taken in phosphate buffer $(15 \mathrm{ml} ; 100$ $\mathrm{m} M, \mathrm{pH} 7.0$ ), the resultant solution was dialysed against water, concentrated by molecular filtration and freeze dried. Yields turned out to be irreproducible $(5-48 \%)$, and degrees of substitution erratic (up to $15 \%$, molar). The low yields and poor results are without any doubt attributable to extensive self-fragmentation of the polyacid imidazoles and contrast with coupling experiments in which saccharin is used as an additive. 
Polyglutamic acid oligopeptide graft, using saccharin as a CDI-additive (general procedure, Scheme 3)

Polyglutamic acid (129 $\mathrm{mg}, 1 \mathrm{mmol} \mathrm{eq})$ and saccharin (220 $\mathrm{mg}, 1.2 \mathrm{mmol})$ were dissolved in dimethylformamide (1-4 $\mathrm{ml}$, depending on the molecular weight of the polymer). In a separate vial, $N, N, N^{\prime}, N^{\prime}$-tetramethylguanidine (TMG, $131 \mu \mathrm{l}, 1.05 \mathrm{mmol}$ ) was slowly added to a stirred suspension of the finely powdered amino acid or oligopeptide (1 mmol) selected. After all solids have gone into solution, $N, N^{\prime}$-carbonyl diimidazole (227 mg, $1.4 \mathrm{mmol}$ ) was added to the solution containing both the polymer and additive to generate the polymeric saccharinic acid imides (30 min stirring). To this solution was added the solution containing the TMG salts of the oligopeptide and the resulting reaction mixture was stirred for 3 days. The solution was added to a phosphate buffer $(25 \mathrm{ml}, 250 \mathrm{mM}$, $\mathrm{pH}$ 7.0) and the resultant solution was dialysed against water, filtered (Millipore HA $0.45 \mu \mathrm{m}$ ) with the aid of a stirred pressure cell, concentrated by molecular filtration, and freeze dried. A 10-20 $\mathrm{mg}$ sample of the product was dissolved in a small volume of deuterium oxide and freeze dried prior to ${ }^{1} \mathrm{H}-\mathrm{NMR}$ analysis. The ${ }^{1} \mathrm{H}-\mathrm{NMR}$ spectra of the products were in accordance with the structures assigned. Degrees of substitution were calculated from proton integrals attributable to structure elements in spacer (e.g. leucine- $\mathrm{CH}_{3}$ ) and backbone. See Table 2 and Fig. 1.

\section{Polyglutamic acid glycine graft}

Polymeric saccharin imides were generated from polyglutamic acid (129 $\mathrm{mg}, 1 \mathrm{mmol}$ eq) as described above. A solution of glycine t-butyl ester hydrochloride $(170 \mathrm{mg}, 1.05$ $\mathrm{mmol})$ and TMG (131 $\mu \mathrm{l}, 1.05 \mathrm{mmol})$ in dimethylformamide $(2 \mathrm{ml})$ was added, and the reaction mixture was stirred for 3 days. The clear solution was diluted with dimethylformamide $(10 \mathrm{ml})$ and then added dropwise to a vigorously stirred aqueous phosphate buffer (600 ml, $100 \mathrm{mM}$, pH 7.0). Fibrous polyglutamic acid glycine t-butyl ester graft precipitates in essentially quantitative yield. The material was washed with water and dried in vacuo. A ${ }^{1} \mathrm{H}-\mathrm{NMR}$ spectrum (DMSO $d_{6}$ ) was in accordance with the structure assigned: $\delta 1.35(\mathrm{~s}, 9 \mathrm{H}, \mathrm{t}-\mathrm{Bu}) ; 1.7-2.5$ (mm, 4H, Glu-CH $\mathrm{CH}_{2}$; 3.7-4.0 (complex multiplet indicating prochirality of Gly$\mathrm{CH}_{2}$ introduced by the polymer, $2 \mathrm{H}$ ); $4.2-$ $4.5(\mathrm{~m}, 1 \mathrm{H}, \mathrm{Glu}-\mathrm{CH})$. Degrees of substition (up to 95\%, molar) were obtained from the ratios of the Glu- $\mathrm{CH}_{2}$ and $\mathrm{t}-\mathrm{Bu}$ $\mathrm{CH}_{3}$ proton integrals.

The protected polymer was dissolved in trifluoroacetic acid $(3 \mathrm{ml})$ and stirred (3 min) and rapidly concentrated in vacuo $\left(20^{\circ} \mathrm{C}\right.$, bath). The solid mass obtained was dissolved in aqueous phosphate buffer (250 $\mathrm{m} M, \mathrm{pH} 7.0,10 \mathrm{ml}$ ), and the $\mathrm{pH}$ of the resulting suspension was readjusted to $\mathrm{pH} 7.0$ by the portionwise addition of sodium carbonate and stirring. The clear solution obtained was further processed, purified and subjected to analysis as described for the polyglutamic acid oligopeptide grafts described above.

Polyglutamic acid oligopeptide graft using a two-step cascade coupling procedure without isolation of intermediate coupling products

Polymeric saccharin imides derived from polyglutamic acid (1 $\mathrm{mmol}$ eq), $N, N^{\prime}$-carbonyl diimidazole and saccharin were generated as described above and allowed to react with an oligopeptide (1.05 $\mathrm{mmol} \mathrm{eq})$ TMG salt in dimethylformamide solution. After incorporation of the oligopeptide of choice ( 3 days), the $C$-terminal groups of the spacer arms present can be reactivated by the addition of $N$-ethyl morpholine (152 $\mu \mathrm{l})$ and a freshly prepared $(<15 \mathrm{~s})$ solution of phenyl dichlorophosphate [49] (180 $\mu \mathrm{l})$ in dimethyl formamide $(0.5 \mathrm{ml})$, respective- 
ly (Scheme 4). The resulting light yellow solution was stirred for $4 \mathrm{~h}$, and the second oligopeptide of choice $(1.05 \mathrm{mmol})$ acid and TMG $(132 \mu \mathrm{l})$ in dimethylformamide $(2 \mathrm{ml})$ was added. The solution was then stirred for 3 days. The polymers containing the elongated oligopeptide grafts (up to 5 amino acid residues) were isolated, purified and subjected to analysis as described above. Degrees of substitution of the oligopeptide fragments were obtained from the proton integrals attributable to appropriate isolated signals in the ${ }^{1} \mathrm{H}-\mathrm{NMR}$ spectra (e.g. TyrAr- $\mathrm{H}$ and Leu- $\mathrm{CH}_{3}$ vs. Glu- $\mathrm{CH}_{2}$ and total of all integrals). Results are given in Table 2 and Fig. 1.

\section{Polyglutamic acid oligopeptide graft adriamycin conjugates (general procedure)}

Polyglutamic acid oligopeptide graft sodium salt ( $1 \mathrm{mmol}$ eq) was dissolved in a small amount of water and slowly passed through an ion-exchange column (polystyrene sulphonate type, pyridinium form, prepared by neutralization of the acid form by pyridine, and washing with distilled water). The pyridinium form of the polypeptide was collected and freeze dried. The voluminous mass was dissolved in a minimum amount of dimethylformamide (magnetic stirring of the viscous solution should be possible). Then, $N$-ethylmorpholine (0.1 mmol eq) and adriamycin hydrochloric acid salt $(0.1 \mathrm{mmol}$ eq) are added. After dissolution of all solids, EEDQ $(0.11 \mathrm{mmol}$ eq) was added. The extent of incorporation of the drug can be monitored by TLC analysis (a minute sample is taken in phosphate buffer $(50 \mu \mathrm{l})$ and subjected to two-dimensional TLC analysis (same solvent), to account for artefacts caused by the presence of dimethylformamide and salts present). In some experiments the addition of more $N$-ethylmorpholine and EEDQ may improve the coupling yield of adriamycin. The reaction mixture was stirred for an additional $24 \mathrm{~h}$, then added to phosphate buffer, and further processed, isolated and analyzed for covalently bound adriamycin (UV) as described for the copolymer of L-glutamic acid and 3 '. $N$-(5-L-glutaminyl) adriamycin. All compounds are believed to be microheterogeneous with respect to molecular weight, degree of substitution of both spacer and drug, but all behave as one entity in dialysis, chromatography and ultrafiltration. All compounds were sterilized by filtration (Millipore HA $0.45 \mu \mathrm{m}$ ), and should be stored in the dark in a freezing chest. Frozen solutions are more resistant to ageing than the solid compounds. Results are given in Table 2.

Incubation of the PGA-Gly-Gly-Leu $(5 \mathrm{mg})$ with papain $(5 \mathrm{mg})$ in phosphate buffer (pH 5.4) gave rise to the formation of adriamycin (TLC) within 5 min.

\section{ACKNOWLEDGMENT}

Thanks are due to professor Federico Arcamone for providing adriamycin.

\section{REFERENCES}

1 A. Trouet, D. Deprez-De Campeneere and C. de Duve, Chemotherapy through lysosomes with DAN-daunomycin complex, Nature New Biol., 239 (1972) 110.

2 J. Kopecek, Controlled biodegradability of polymers - A key to drug delivery systems, Biomaterials, 5 (1984) 19.

3 T.A. Connors, Possible pro-drugs in cancer chemotherapy, Chem. Ind., (1980) 447.

4 P.K. Chakavarty, P.L. Carl, M.J. Weber and J.A. Katzenellenbogen, Plasmin-activated prodrugs for cancer chemotherapy. 2. Synthesis and biological activity of peptidyl derivatives of doxorubicin, J. Med. Chem., 26 (1983) 638.

5 G. Atassi, M. Duarte-Karim and H.G. Tagnon, Comparison of adriamycin with DNA-adriamycin complex in the chemotherapy of experimental tumors and metastases, Eur. J. Cancer, $11(1975) 309$.

6 E. Hurwitz, R. Maron, R. Arnon and M. Sela, Fab-dimers of antitumor immunoglobulins as covalent carriers of daunomycin, Cancer Biochem. Biophys., 1 (1976) 197. 
7 Y. Tsukada, W.K.D. Bischof, N. Hibi, H. Hirai, E. Hurwitz and M. Sela, Effect of a conjugate of daunomycin and antibodies to rat $\alpha$-fetoprotein on the growth of $\alpha$-fetoprotein-producing tumor cells, Proc. Natl. Acad. Sci. U.S.A., 79 (1982) 621.

8 E. Hurwitz and J. Pitha, In vitro and in vivo efficacy of conjugates of daunomycin with antibodies, Immunol. Rev., 62 (1982) 5.

9 F. Zunino, R. Gambetta and S. Penco, Conjugated products of daunorubicin and a protein, Belg. BE $893,109,30$ Aug. 1982; GB Appl. 81/14,167 May 1981, Biologic activity of daunorubicin linked to proteins via the methyl ketone side chain, Tumori, 67 (1981) 521.

10 A. Trouet, M. Masquelier, R. Baurain and D. Deprez-De Campeneere, A covalent linkage between daunorubicin and proteins that is stable in serum and reversible by lysosomal hydrolases, as required for a lysosomotropic drug-carrier conjugate: In vitro and in vivo studies, Proc. Natl. Acad. Sci. U.S.A., 79 (1982) 626.

11 E. Hurwitz, Specific and non-specific macromolecule-drug conjugates for the improvement of cancer chemotherapy, Biopolymers, 22 (1983) 557.

12 E.P. Goldherg, R.N. Terry and M. Levy, Polymeric drugs with tissue binding properties for localized chemotherapy, Org. Coat. Plast. Chem., 44 (1981) 132 .

13 E. Hurwitz, M. Wilchek and J. Pitha, Soluble macromolecules as carriers for daunorubicin, J. Appl. Biochem., 2 (1980) 25.

14 F. Zunino, F. Giuliani, G. Savi, T. Dasdia and R. Gambetta, Antitumor activity of daunorubicin linked to poly-L-aspartic acid, Int. J. Cancer, 30 (1982) 465.

$15 \mathrm{~T}$. Kitao and $\mathrm{K}$. Hattori, Concanavalin $\mathrm{A}$ as a carrier for daunomycin, Nature, 265 (1977) 81.

16 F. Levi Schaffer, A. Bernstein, A. Meshorer and $R$. Arnon, Reduced toxicity of daunorubicin by conjugation to dextran, Cancer Treat. Rep., 66 (1982) 107.

17 G. Decher, M. Emmelius and H. Ringsdorf, Synthesis and antitumor activity of dauno. rubicin-containing polymers, Proceedings of the 26th IUPAC Microsymposium on Polymers in Medicine and Biology, Prague, July 9-12, 1984.

18 G.F. Rowland, G.J. O'Neill and D.A.L. Davies, Suppression of tumor growth in mice by drugantibody conjugate using a novel approach to linkage, Nature, 255 (1975) 487.
19 T. Hirano, W. Klesse and H. Ringsdorf, Polymeric derivatives of activated cyclophosphamide as drug delivery systems in antitumor chemotherapy. Pharmacologically active polymers, 20, Makromol. Chem., 180 (1979) 1125.

20 Y. Kato, M. Saito, H. Fukushima, Y. Takeda and T. Hara, Antitumor activity of 1- $\beta$-D -arabinofuranosylcytosine conjugated with polyglutamic acid and its derivative, Cancer Res., 44 (1984) 25.

21 R.V. Petersen, J.M. Anderson, S.M. Fang, J. Feijen, D.E. Gregonis and S.W. Kim, Studies on norethindrone covalently bonded to poly$N^{5}$-(3-hydroxy propyl)-L-glutamine, Polym. Prepr., 20 (1979) 20.

22 R.V. Petersen, C.G. Anderson, S. Fang, D.E. Gregonis, S.W. Kim, J. Feijen, J.M. Anderson and S. Mitra, Controlled release of progestins from poly $(\alpha$-amino acid) carriers, in: $R$. Baker (Ed.), Controlled Release of Bioactive Materials, Academic Press, New York, 1980, pp. 4560.

23 J. Feijen, D.E. Gregonis, C. Anderson, R.V. Peterson and J. Anderson, Coupling of steroid hormones to biodegradable poly $(\alpha$-amino acids) I: Norethindrone coupled to poly- $N^{5}$-(3-hydroxypropyl)-L-glutamine, J. Pharm. Sci., 69 (1980) 871.

24 S.W. Kim, R.V. Petersen and J. Feijen, Poly. meric drug delivery systems, in: E.J. Ariens (Ed.), Medicinal Chemistry, Vol. X, Chap. 5, Drug design, Academic Press, New York, 1980.

25 W.A.R. van Heeswijk, G.J. Brinks and J. Feijen, Synthesis and characterization of covalently bound polymer-hormone conjugates for the controlled release of hormones, in: E. Chiellini and P. Giusti (Eds.), Polymers in Medicine, Biomedical \& Pharmacological Applications, Plenum Press, New York, 1983, p. 147.

26 K.R. Sidman, A.D. Schwope, W.D. Steber, S.E. Rudolph and S.B. Poulin, Biodegradable, implantable sustained release systems based on polyglutamic acid copolymers, $J$. Membrane Sci., 7 (1980) 277.

27 H.R. Dickinson, A. Hiltner, D.F. Gibbons and J.M. Anderson, Biodegradation of a poly $(\alpha$ amino acid) hydrogel. I. In vivo, J. Biomed. Mater. Res., 15 (1981) 577.

28 H.R. Dickinson and A. Hiltner, Biodegradation of a poly( $\alpha$-amino acid) hydrogel. II. In vitro, J. Biomed. Mater. Res., 15 (1981) 591.

29 E.S. Barrow and J.B. Graham, Polyglutamic acid and polyaspartic acid: Synthetic polypeptides with predominantly factor VIII-like coagulant activity, Proc. Soc. Exp. Biol. Med., 152 (1976) 160 . 
30 A.D. Kenny, Evaluation of sodium poly- $\alpha-L$ glutamic as a plasma expander, Proc. Soc. Exp. Biol. Med., 100 (1959) 778.

31 L. Gros, H. Ringsdorf and H. Schupp, Polymere Antitumormittel auf molecular und cellularer Basis?, Angew. Chem., 93 (1981) 311.

32 S. Eksborg, Extraction of daunorubicin and doxorubicin and their hydroxyl metabolites: Self-association in aqueous solution, J. Pharm. Sci., 67 (1978) 782 .

33 S.R. Martin, Absorption and circular dichroic spectral studies on the self-association of daunorubicin, Biopolymers, 19 (1980) 713.

34 E.R. Blout and R.H. Karlson, The synthesis of high molecular weight poly- $\gamma$-benzyl-Lglutamates, J. Amer. Chem. Soc., 78 (1956) 941.

35 M. Idelson and E.R. Blout, High molecular weight poly- $\alpha$-L-glutamic acid; preparation, J. Amer. Chem. Soc., 80 (1958) 4631.

36 E.R. Blout, R.H. Karlson, P. Doty and B. Hargitay, Polypeptides. I. The synthesis and molecular weight of high molecular weight polyglutamic acids and esters, J. Amer. Chem. Soc., 76 (1954) 4492.

37 St. Guttmann and R.A. Boissonnas, Synthèse du $\mathrm{N}$-acétyl-L-séryl-L -tyrosyl-L-séryl-L-méthionyl$\gamma$-L-glutamate de benzyle et des peptides apparantés, Helv. Chim. Acta, 41 (1958) 1852.

38 W.D. Fuller, M.S. Verlander and M. Goodman, A procedure for the facile synthesis of amino acid $N$-carboxyanhydrides, Biopolymers, 15 (1976) 1969.

39 A. Tsutsumi, B. Perly, A. Forchioni and C. Chachaty, A. magnetic resonance study of the segmental motion and local conformations of poly(L-glutamic acid) in aqueous solutions, Macromolecules, 11 (1978) 977.

40 O. Pieroni, J.L. Houben, A. Fissi, P. Constantino and $F$. Ciardelli, Reversible conformational changes induced by light in poly (L-glutamic acid) with photochromic side chains, J. Amer. Chem. Soc., 102 (1980) 5915.

41 R.B. Woodward, R.A. Olofson and H. Mayer, A useful synthesis of peptides, Tetrahedron, 22 , suppl. 8 (1966) 321.

$42 \mathrm{M}$. Bodanszky and J. Martinez, Side reactions in peptide chemistry. 8 . On the phenacyl group in the protection of the beta-carboxyl function of aspartyl residues, J. Org. Chem., 43 (1978) 3071.

43 A.R. Battersby and J.C. Robinson, Studies on specific chemical fission of peptide links. Part I. The rearrangement of aspartyl and glutamyl peptides, J. Chem. Soc., (1955) 269.

44 R. Paul and G.W. Anderson, $N, N^{\prime}$-Carbonyldiimidazole, a new peptide forming reagent, J. Amer. Chem. Soc., 82 (1960) 4596.

45 T. Mukaiyama, R. Matsueda and M. Suzuki, Peptide synthesis via the oxidation-reduction condensation by the use of $2,2^{\prime}$-dipyridylsulfide, Tetrahedron Lett., 22 (1970) 101.

46 B. Belleau and G. Malek, A new convenient reagent for peptide synthesis, J. Amer. Chem. Soc., 90 (1968) 1651.

47 Y. Kiso and H. Yayima, 2-Isobutoxy-1-isobutoxycarbonyl-1,2-dihydroquinoline as a coupling reagent in peptide synthesis, J. Chem. Soc. Chem. Comm., (1972) 949.

48 F. Micheel and M. Lorenz, Peptidsynthesen mit gemischten Anhydriden aus $N$-Acyl-aminosauren und Saccharin, Justus Liebigs Ann. Chem., 698 (1966) 242.

49 H. Liu, W. Hong Chan and S.P. Lee, Convenient procedures for the esterification of carboxylic acids, Tetrahedron Lett., 46 (1978) 4461.

$50 \mathrm{M}$. Satoh, J. Komiyama and T. Iijima, Viscometric study of poly( $\alpha-\mathrm{L}$-glutamic acid) in $\mathrm{NaCl}$ solution, Colloid Polym. Sci., 258 (1980) 136.

51 B.R. Jennings, G. Spach and T.M. Schuster, Specific aggregation of poly $(\alpha-\mathrm{L}-$ glutamic acid $)$ and hysteresis effects in aqueous solutions. I. Influence of temperature-dependent aggregation on the optical rotation of PGA, Biopolymers, 6 (1968) 635

$52 M$. Morcellet and C. Loucheux, Viscosity/molecular weight relationship of poly $(\alpha-L$-glutamic acid) in water and in water/dioxane mixtures, Biopolymers, 15 (1976) 1857.

53 M.K. Anwer and A.F. Spatola, An advantageous method for the rapid removal of hydrogenolysable protecting groups under ambient conditions; Synthesis of leucine-enkephalin, Synthesis, (1980) 929. 